\title{
Scarpa Fascia versus Rectus Sheath Plane in Lipoabdominoplasty Flap Dissection: Comparative Study
}

\author{
HELMY ELWAKEEL, M.D.; MOHAMED H. ABOUARAB, M.D. and HASSAN M. KHOLOSY, M.D. \\ The Department of Plastic Surgery, Faculty of Medicine, Alexandria University, Egypt
}

\begin{abstract}
Background: Abdominoplasty and lipoabdominoplasty are frequently performed aesthetic procedures to improve the contour of the abdomen and flanks. The improvement obtained would positively impact the patient's self-image and life quality. A lot of potential complications would compromise surgeon/patient satisfaction, the most frequent being seroma formation. A lot of measures/techniques were advocated to reduce seroma incidence including the use of suction drain, dead space obliteration by quilting sutures, and preservation of infraumbilical Scarpa fascia/deep fat layer. The latter is the focus of the current comparative study.

Patients and Methods: 40 full lipoabdominoplasty cases were randomized into 2 equal groups based on the infraumbilical dissection plane. Group A with traditional rectus sheath dissection plane and group B with supra Scarpa dissection plane. Post-operative drainage volume, time of drain removal, and incidence of symptomatic seromas were documented.

Results: Drainage volume and duration of drainage were significantly lower in the supra Scarpa dissection group (B) than those of the rectus plane group (A) $(p<0.001)$. Clinically evident seroma was detected in 3 cases of group (A) and one case of group (B). All resolved after 2-3 aspirations in outpatient settings. Both groups were homogenous regarding BMI, age, volume of lipoaspirate, weight of excised dermofat and mean operative time.
\end{abstract}

Conclusion: Scarpa fascia/deep fat preservation significantly reduced the drainage volume and duration. A lower seroma incidence was also observed.

Key Words: Scarpa fascia - Lipoabdominoplasty - Seroma.

\section{INTRODUCTION}

Abdominoplasty is a frequently performed surgical operation to improve the shape of the anterior trunk and waist [1]. A satisfactory improvement of abdominal shape is always obtained, together with occasional complications, the most frequent being seroma formation [2-6], especially with the classic/traditional abdominoplasty operations, in which disruption of abdominal flap lymphatic channels is incriminated by many reports [5-7] in seroma formation. Traditional abdomino- plasty relied upon basic principles of lower abdominal (suprapubic) skin incision, wide undermining of the dermofat flap in premuscular plane to costal margins/xiphoid process level, midline plication, resection of the redundant lower abdominal dermofat, umbilical translocation, and skin closure. This traditional approach underwent a lot of modifications to improve the results and/or to reduce the potential complications. Techniques and measures described in the literature to reduce seroma incidence included: Use of suction drains, infraumbilical deep fat preservation (by dissection of just above or beneath Scarpa's fascia) [7-14], use of quilting sutures [15-20], and fibrin sealants [21].

Typical abdominoplasty dissection is performed directly over anterolateral abdominal wall muscles and rectus sheath. Deep fat preservation with supra (or just beneath) Scarpa plane of dissection in the infraumbilical region was proposed by many authors as a mean of reduction of drainage time and seroma rate [7-14]. The suggested mechanisms included preservation of lymphatic and vascular channels within the Scarpa fascia and deep fat and better adhesion and healing between Scarpa/deep fat and the abdominal flap explained by tissue similarity. Also, the irregular surface of Scarpa/deep fat and its more flexible nature (compared to the tough rectus fascia) would provide impedance to shearing between the healing surfaces [7-14].

The current study represents an analysis of lipoabdominoplasty cases performed either in rectus sheath (premuscular) or Scarpa fascia plane of dissection, focusing upon the volume of drainage, time of drain removal, and seroma incidence.

Aim:

Reporting the effect of infraumbilical Scarpa fascia/deep fat preservation in lipoabdominoplasty on time of drain removal and seroma incidence. 


\section{PATIENTS AND METHODS}

Forty lipoabdominoplasty cases were randomized into 2 groups based on the infraumbilical dissection plane:

- Group A: 20 lipoabdominoplasty procedures with rectus sheath dissection plane.

- Group B: 20 lipoabdominoplasty procedures with supra Scarpa dissection plane.

Randomization was done by alternating patients to each study group. The study was performed between February 2015 - December 2019, in Alexandria Main University Hospital and private practice. Both groups received the same lipoabdominoplasty technique described below, the mere difference was the plane of dissection. The study was approved by the faculty research ethical committee.

\section{Inclusion criteria:}

- Female with moderate to severe abdominal diastasis and skin/fat excess candidates for a full abdominoplasty.

- BMI $<35$.

- Realistic expectations.

- Medically fit.

\section{Exclusion criteria:}

- Post-bariatric cases candidates for belt lipectomy.

- Cases with mainly intraabdominal (visceral) fat.

- Abdominal scars excluding cesarean section.

- Significant medical or mental disability and unrealistic expectations.

- Smoking.

Before surgery informed consent was taken from patients. Cases with a hemoglobin level less than $11 \mathrm{gm} / \mathrm{dl}$ were postponed till the correction of their anemia.

\section{Marking:}

Marking was done in a standing position, this included the midline from the xiphoid process to suprapubic region, topographic marking for liposuction, and lower flap incision stating centrally at the suprapubic region, preserving $7 \mathrm{~cm}$ of mons pubis height, and gently curving upwards $2 \mathrm{~cm}$ above inguinal crease towards the iliac crest. The lateral incision limit was determined by the extent of the lower abdominal skin fold.
Surgical technique:

In group (A) premuscular dissection:

All patients were operated on under general anesthesia. Surgery started by tumescent fluid infiltration (1mg adrenaline $+10 \mathrm{ml} 2 \%$ xylocaine per liter of saline) in the supraumbilical region and flanks utilizing the super-wet technique. Xylocaine was added to provide few hours of post-operative analgesia. A $200 \mathrm{ml}$ of the tumescent fluid was infiltrated in the infraumbilical region to the muscles/rectus sheath plane to ensure bloodless field during flap dissection.

Liposuction of the flanks and supraumbilical area was performed using Mercedes tip 4mm cannula. The target was the extraction of the whole deep (sub-Scarpa) fat deposits. Next, the previously marked suprapubic incision line was deepened through subcutaneous fat and Scarpa fascia to the level of the abdominal muscles/rectus sheath. The dermofat flap elevation proceeded in this plane using electrocautery. Supraumbilical flap elevation was limited to just $1-2 \mathrm{~cm}$ lateral to the medial edge of the divaricated recti. Rectus sheath plication followed, 1st by raw of interrupted Vicryl 0 suture then continuous locked Polyprolen 1 suture. With the patient semi-flexed to 30 degrees, the proper level of upper incision to excise the excess lower flap was determined and excised. Now the undersurface of the upper flap is examined, and any remaining deep (sub-Scarpa) fat is surgically excised. This was followed by umbilical transposition, insertion of 2 closed suction drains, and wound closure in 2 layers.

\section{In group (B) supra Scarpa dissection:}

Received the same lipoabdominoplasty procedure described above for Group (A) except for the infraumbilical dissection plane which was modified to supra Scarpa level. In this group, the abdominoplasty flap incision was only deepened to Scarpa fascia level, which was left intact and initial infraumbilical flap elevation proceeded just superficial to it. Just 2-3 blow the umbilicus the dissection plane was gradually deepened reaching the classical premuscular plane at the level of the umbilicus. In the central infraumbilical region (between the medial edges of the recti) the Scarpa fascia and deep fat were excised to permit later midline plication (Fig. 1-Right).

At the end of the procedure, the preserved Scarpa fascia and deep fat and were approximated at the midline over the plicated rectus sheath together using 3-4 interrupted Vicryl 2/0 sutures (Fig. 1-Left). 


\section{Post-operative:}

Both groups received the same post-operative protocol including proper hydration and encouragement of early ambulation starting from the night of surgery. Prophylactic low molecular weight heparin ( 1 unit/kg/day) was initiated 6 hours postoperatively and stopped after 2-3 days when patients were able to ambulate regularly. Compression garment was used for 8 weeks, and excessive or strenuous activity was avoided for at least 6 weeks. Drains output were calculated daily and drains were removed when daily drainage per drain was $30 \mathrm{ml}$ or less.

\section{Follow-up:}

Early follow-up visits were arranged at the 1st, $2^{\text {nd }}, 3^{\text {rd }}$, and $4^{\text {th }}$ week post-operative. The assessment included early complications including flap vascular compromise, seroma, wound dehiscence, infection, or delayed healing. Late follow-up 6 months post-operative assessed patients' satisfaction and late results. Patients were asked to grade their satisfaction with results as either: Very satisfied, satisfied, neutral, dissatisfied, or very dissatisfied.

Study analysis focused upon patient age, comorbidities, BMI, amount of daily drainage, total drainage, time of drains removal, and incidence of clinically evident seroma at 2 weeks, 3 weeks, and 4 weeks post-operative follow-up visits and other possible complications.

\section{RESULTS}

Study results are summarized in Table (1). Both groups were almost comparable regarding patients' age, BMI, weight of excised pannus and volume of lipoaspirate and mean operative time. No cases needed blood transfusion in both groups.

Mean total drainage volume and mean time to drain removal were $(431.3 \mathrm{ml} \pm 89.7)$ and (4.3 days \pm 0.72 ) respectively in group B with Scarpa fascia preservation. This was significantly lower $(p 0.001)$ compared to group (A) Figures of $(866.3 \mathrm{ml} \pm$ $126.4)$ and (9 days \pm 2 ) respectively.

A clinically evident seroma was seen in 3 out of 20 patients $(15 \%)$ in group (A) compared to 1 out of 20 cases (5\%) in group (B). All were managed conservatively with repeated needle aspiration every 4-5 days. All resolved after 2-3 aspirations.

No major or minor abdominal flap loss was seen in both groups, minor wound dehiscence occurred in 2 cases of group A and one case of group B.

Only 32 cases ( 15 group A \& 17 group B) were reachable at 6 months post-operative for assessment of patients' satisfaction and results. Cases were very satisfied or satisfied with the results (Table 2). All presented cases maintained satisfactory abdominal contour (Figs. 2,3).

Table (1): Comparison between the two studied groups according to different parameters.

\begin{tabular}{|c|c|c|c|}
\hline & $\begin{array}{l}\text { Group A } \\
(\mathrm{n}=20)\end{array}$ & $\begin{array}{l}\text { Group B } \\
(\mathrm{n}=20)\end{array}$ & $p$ \\
\hline \multicolumn{4}{|l|}{ Age (years): } \\
\hline $\begin{array}{l}\text { Mean } \pm \text { SD. } \\
\text { (Min. - Max.) }\end{array}$ & $\begin{array}{l}39.9 \pm 7.1 \\
(28-57)\end{array}$ & $\begin{array}{l}42.4 \pm 6.5 \\
(31-55)\end{array}$ & 0.807 \\
\hline \multicolumn{4}{|l|}{$B M I\left(k g / m^{2}\right):$} \\
\hline $\begin{array}{l}\text { Mean } \pm \text { SD. } \\
\text { Median (Min. - Max.) }\end{array}$ & $\begin{array}{l}31.9 \pm 1.9 \\
(27.8-34.3)\end{array}$ & $\begin{array}{l}32.2 \pm 2.2 \\
(28.3-34.6)\end{array}$ & 0.847 \\
\hline \multicolumn{4}{|l|}{ Drainage (volume $/ \mathrm{ml})$ : } \\
\hline $\begin{array}{l}\text { Mean } \pm \text { SD. } \\
\text { (Min. - Max.) }\end{array}$ & $\begin{array}{l}866.3 \pm 126.4 \\
(580-1100)\end{array}$ & $\begin{array}{l}431.3 \pm 89.7 \\
(290-605)\end{array}$ & $<0.001 *$ \\
\hline \multicolumn{4}{|l|}{ Duration of drainage } \\
\hline $\begin{array}{l}\text { Mean } \pm \text { SD. } \\
\text { (Min. - Max.) }\end{array}$ & $\begin{array}{l}9 \pm 2 \\
(6-14)\end{array}$ & $\begin{array}{l}4.3 \pm 0.72 \\
(3-6)\end{array}$ & $<0.001 *$ \\
\hline \multicolumn{4}{|l|}{ Lipoaspirate (vol/ml): } \\
\hline $\begin{array}{l}\text { Mean } \pm \text { SD. } \\
\text { (Min. - Max.) }\end{array}$ & $\begin{array}{l}2674 \pm 414.3 \\
(1900-3450)\end{array}$ & $\begin{array}{l}2584 \pm 392 \\
(2100-3400)\end{array}$ & 0.703 \\
\hline \multicolumn{4}{|l|}{ Weight of pannus/gm: } \\
\hline $\begin{array}{l}\text { Mean } \pm \text { SD. } \\
\text { (Min. - Max.) }\end{array}$ & $\begin{array}{l}1737.5 \pm 296.7 \\
(1250-2341)\end{array}$ & $\begin{array}{l}1678 \pm 271.9 \\
(1250-2125)\end{array}$ & 0.830 \\
\hline Seroma incidence & $3(15 \%)$ & $1(5 \%)$ & $\mathrm{FE}_{p=0.605}$ \\
\hline $\begin{array}{l}\text { Operative time (minutes) } \\
\text { Mean } \pm \text { SD. } \\
\text { (Min. - Max.) }\end{array}$ & $\begin{array}{l}178.5 \pm 15.3 \\
(158-190)\end{array}$ & $\begin{array}{l}183 \pm 17.2 \\
(155-193)\end{array}$ & 0.813 \\
\hline \multirow{2}{*}{\multicolumn{4}{|c|}{$\begin{array}{l}\text { SD: Standard deviation. } \\
\text { FE: Fisher Exact } \\
p \text { : } p \text {-value for comparing between the studied groups. } \\
* \text { : Statistically significant at } p \leq 0.05 \text {. }\end{array}$}} \\
\hline & & & \\
\hline & Group A & Grou & p B \\
\hline No. of cases & 15 & 1 & \\
\hline Very satisfied & 11 & 1 & \\
\hline Satisfied & 4 & 5 & \\
\hline
\end{tabular}



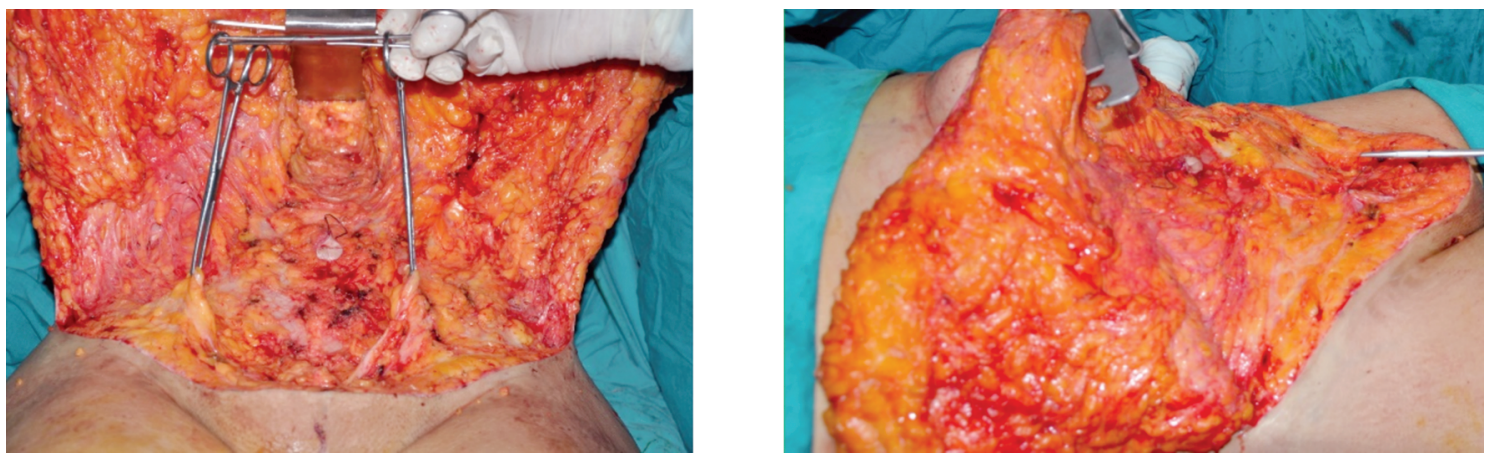

Fig. (1): (Left) Intra operative view showing the preserved lower abdominal Scarpa fascia and sub Scarpa fat except centrally over the diastasis of recti. Limited supra umbilical dissection is also seen. (Right) Same case after rectus sheath plication. The preserved Scarpa fascia is also approximated in the midline to offer uniform platform beneath the abdominal flap.
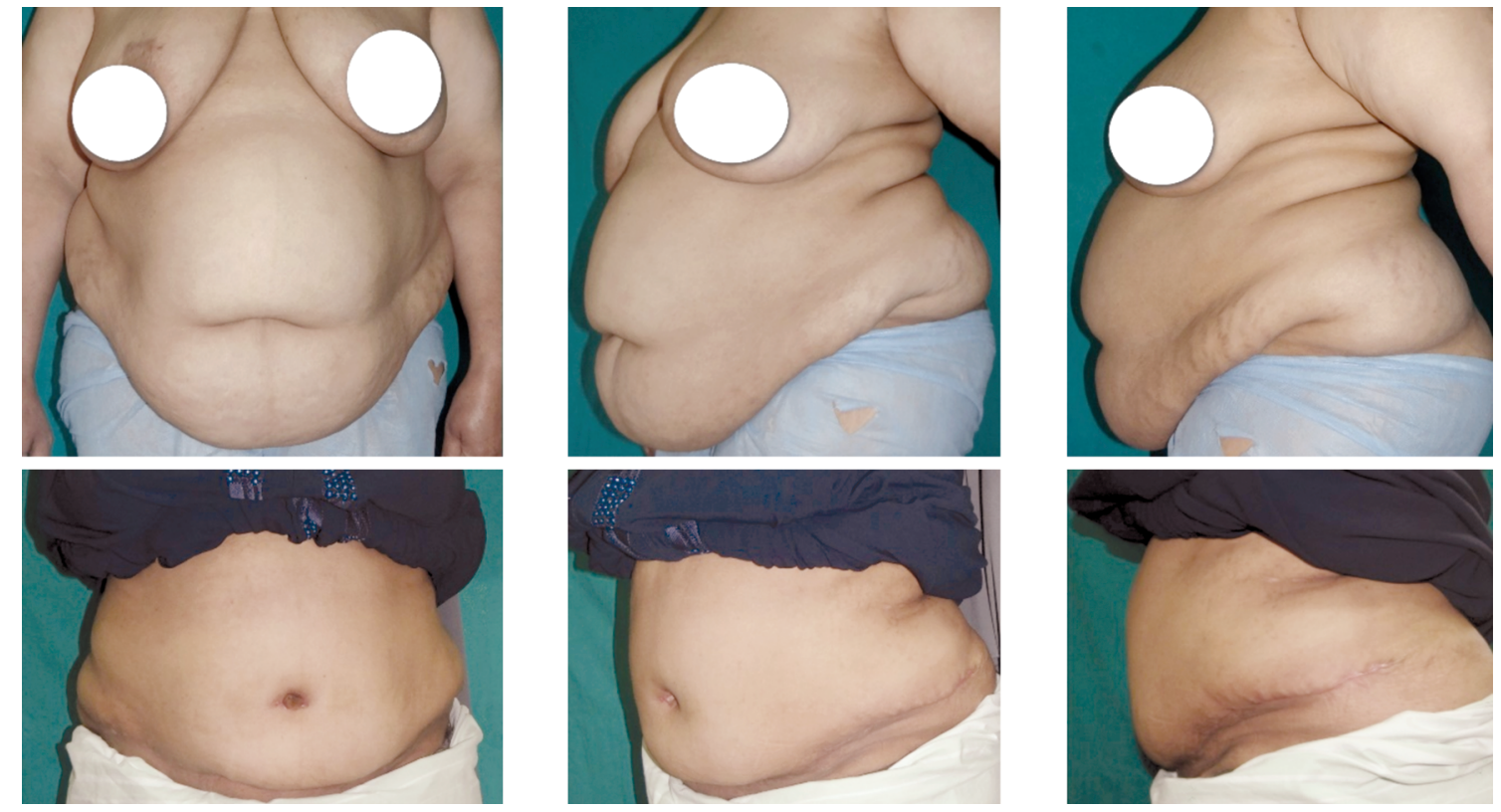

Fig. (2): Group (A) 47 y old patient, BMI 34.3. (Above) Pre-operative. (Blow) 6 months post-operative abdominal contour.
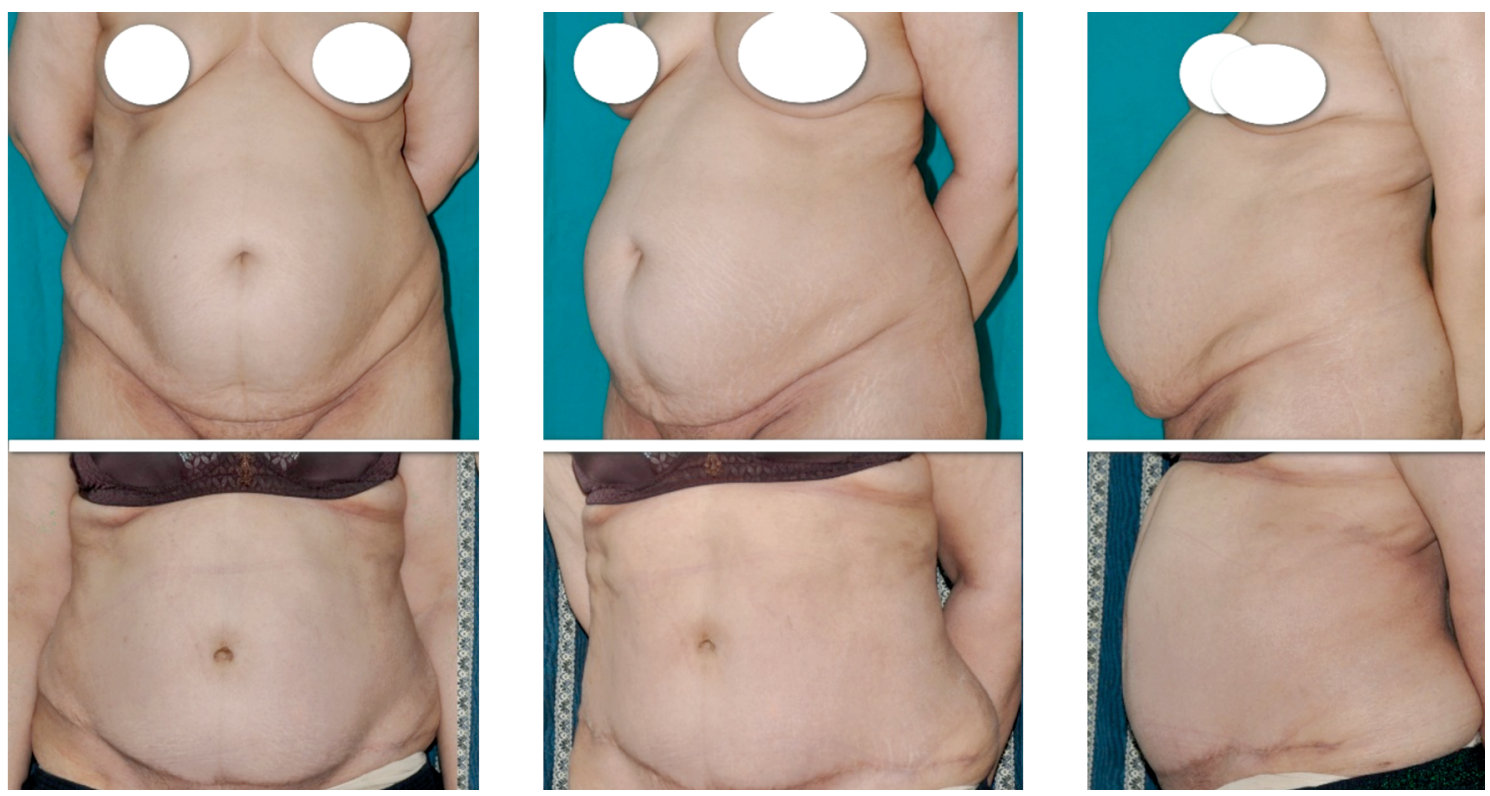

Fig. (3): Group (B) 45 y old patient, BMI 29.3. (Above) Pre-operative (Blow) 6 months post-operative abdominal contour. 


\section{DISCUSSION}

Seroma is the most common abdominoplasty complication with a reported incidence between $3.6-60 \%$ [2-7,28]. Probably this is the driving force for many authors to find an effective and safe measure or surgical technique for seroma reduction. A lot of measures were advocated including the use of suction drains, preservation of infraumbilical Scarpa fascia/deep fat [7-15], quilting sutures [1520], and use of fibrin sealant [21].

The Scarpa (superficial) fascia divide the abdominal subcutaneous fat is divided into superficial and deep layers. The latter is relatively thin in the lower abdomen representing $19 \%$ of the subcutaneous fat thickness $[\mathbf{2 2 , 2 3 ]}$.

A more superficial plane of dissection in the infraumbilical region was first reported by Le Louarn [8], in one of the earliest lipoabdominoplasty reports (lipoabdominoplasty term name was coined and popularized later by Saldanha [10]). Le Louran [8] reported a series of 65 abdominoplasty cases with no seroma. His procedure entailed liposuction of the entire abdomen both superficial and deep to Scarpa fascia. The infraumbilical abdominoplasty flap was then raised in a plane just beneath the Scarpa fascia preserving the remaining deep fat and its lymphovascular channels. The plane was deepened to the rectus sheath level above the umbilicus with limited lateral dissection. Later many authors [7,9-15] applied this concept of Scarpa fascia/deep fat preservation. Reported benefits included a reduced drainage volume, time to drain removal, hospital stay, and seroma rate. Another interesting advantage of the supra Scarpa plane of dissection was reported by Novais et al., [26] they demonstrated better regain of supraumbilical sensation after abdominoplasty with supra Scarpa dissection plane in the infraumbilical region.

The underlying mechanism of seroma reduction is not fully understood/explained and even debated [24]. The proposed explanation included the preservation of deep lymphatic vessels within the subScarpa fat, the preserved vascularity within the fat/fascia, and better healing with the undersurface of the abdominoplasty flap $[\mathbf{7 , 1 0 , 1 2 - 1 4 , 2 5 ]}$.

In the current study using a supra Scarpa plane of dissection (group B) was associated with a significant reduction of volume of drainage, early drain removal $(p<0.001)$ compared to the traditional rectus sheath dissection plane (group A). Earlier drain removal in group B positively improved patients' comfort, mobility, and recovery. Intraoperative blood loss during supra Scarpa flap dissec- tion was observationally comparable to the traditional rectus sheath plane, yet the former plane was tricky to follow in some cases with poorly defined discontinuous Scarpa fascia layer. None of the cases received blood transfusion.

Incidence of clinically evident seroma also was lower in group B (1 out of 20 cases) compared to group A ( 3 out of 20 cases). The small sample size and the low overall incidence of seroma compromised obtaining a significance of this seroma risk reduction on a statistical basis. Seroma detection was only clinical, carefully checking any fluctuant bulge or swelling after drain removal on the 2 nd. week visit and later, the typical time of seroma formation. Ultrasound examination was used for seroma detection in some trials [15], and clearly, this is more sensitive than clinical examination alone. The latter would only miss a small, often self-resolving collection/seroma, this would apologies for the lack of US examination for seroma detection in this study and other reports [13,28].

In the current report, both groups were homogenous regarding age, BMI, the weight of excided panniculus, and volume of lipoaspirate. Both groups received the same lipoabdominoplasty procedure, the only difference was the infraumbilical plane of dissection.

In a retrospective analysis of 112 lipoabdominoplasty procedures with Scarpa fascia/deep fat preservation Ali A., et al., [7] reported a low seroma rate of $3.6 \%$ and a mean of 2 days to drain removal. The high BMI of studied cases (mean of 35.2) with significant lipodystrophy, diastasis, large abdominal panniculus, and moons pubis ptosis justified the authors' term "huge abdomen" for cases description.

Koller [14] in a prospective study comparing two classic abdominoplasty groups ( 25 cases each) using either supra Scarpa or supra muscular plane, founded that the supra Scarpa plane reduced the seroma risk and drainage volume significantly. In his report time to drain removal was almost the same. An ultrasonically activated scalpel was used for flap dissection in both groups, a measure that is proposed to reduce drainage/seroma rate compared to electrocautery [27].

In a large prospective study by Costa et al., [13] comparing supra Scarpa versus supra muscular plan of dissection with traditional full abdominoplasty with occasional flak liposuction, they reported a much lower (2.8\%) seromas rate with Scarpa fascia preservation compared to the supra muscular plane (18.8\%). 
In a retrospective analysis of 446 cases submitted to lipoabdominoplasty with Scarpa fascia preservation versus 494 cases of traditional abdominoplasties, Saldanha [28] reported a reduction of seroma risk from $60 \%$ to only $0.4 \%$ with lipoabdominoplasty and Scarpa preservation. This dramatic seroma rate reduction probably reflects both the beneficial effect of the lipoabdominoplasty approach with limited undermining plus Scarpa fascia/deep fat preservation. In the current study, both groups received the same lipoabdominoplasty technique and the reported less dramatic seroma risk reduction would reflect the effect of the different dissection planes used.

Great variability was noticed between reports [8-14,29] comparing the traditional rectus sheath plane of dissection to a more superficial dissection plane. The first aspect of such variability was the superficial plane of dissection itself, whatever just above $[\mathbf{9 , 1 0 , 1 2 - 1 4}$, or just blow Scarpa fascia $[\mathbf{8 , 1 1}]$ or even deeper plane within the deep fat preserving only the loose areolar fatty layer over the abdominal muscles [11]. Other aspects of variability included the technique of full abdominoplasty used (traditional [12,13] or lipoabdominoplasty [7-9]), the BMI of studied cases, mode of dissection (electrocautery [29], avulsion [13,29], knife [11] or ultrasonically activated scalpel [14]). This variability would make a direct comparison of various studies impractical, a matter further complicated by the presence of other technical differences between the two groups in the same report apart from Scarpa preservation [28], yet a clear opinion of the beneficial effect of Scarpa fascia/deep fat preservation could be concluded from those reports and the present study.

Literature reports of Scarpa fascia/deep fat preservation reported satisfactory aesthetic result/ abdominal contour $[\mathbf{8 - 1 4 , 2 8}$, as the retained lateral deep fat layer is considerably thin [22] and could be modified by liposuction as indicated [8-10,28]. In the current series, high patient satisfaction was comparable among both groups at 6 months followup and post-operative abdominal contour was satisfactory in all cases (both groups) during early and late follow-up. This was judged within the context of patients' preoperative abdominal contour and the relatively high BMI (Table 1) of all studied cases (both groups). None of the enrolled cases promised or expected flat abdominal contour owing to their high BMI with intraabdominal fat partially contributing to the abdominal contour. All cases were encouraged for initial weight reduction before surgery, but few were complaint. Any cases with unrealistic expectations or presenting mainly with intraabdominal fat excess were excluded. This probably underly the high patient's satisfaction reported in this series.

\section{Conclusion:}

Supra Scarpa plane of dissection in lipoabdominoplasty significantly reduced time to drain removal and drainage volume. A lower seroma rate was also noticed.

\section{REFERENCES}

1- International Society of Aesthetic Plastic Surgery. ISAPS global statistics: The international study on aesthetic/cosmetic procedures performed in 2019. Available at: https:// www.isaps.org/medical-professionals/isaps-globalstatistics/. Accessed Dec 2020.

2- Uchelen J.H., Werker P.M. and Kon M.: Complications of abdominoplasty in 86 patients. Plast. Reconstr. Surg., 107: 1869-1873, 2001.

3- Stewart K.J., Stewart D.A., Coghlan B., Harrison D.H., Jones B.M. and Waterhouse N.: Complications of 278 consecutive abdominoplasties. J. Plast. Reconstr. Aesthet. Surg., 59: 1152-1155, 2006.

4- Hensel J.M., Lehman J.A. Jr., Tantri M.P., Parker M.G., Wagner D.S. and Topham N.S.: An outcome analysis and satisfaction survey of 199 consecutive abdominoplasties. Ann. Plast. Surg., 46: 357-363, 2001.

5- Kim J. and Stevenson T.R.: Abdominoplasty, liposuction of the flanks, and obesity: Analyzing risk factors for seroma formation. Plast. Reconstr. Surg., 117: 773-779; discussion 780-781, 2006.

6- Zimman O.A., Butto C.D. and Ahualli P.E.: Frequency of seroma in abdominal lipectomies. Plast. Reconstr. Surg., 108: 1449-1451, 2001.

7- Ali A., Elbarbary A.S., Farag M. and Saleh M.A.: Technical Considerations in Abdominoplasty of Huge Abdomen. The American Journal of Cosmetic Surgery, 29 (4): 252$259,2012$.

8- Le Louarn C.: Partial subfascial abdominoplasty. Aesthetic Plast. Surg., 20: 123-127, 1996.

9- Saldanha O.R., Pinto E.B.S, Matos W.N., et al.: Lipoabdominoplasty without undermining. Aesthet. Surg. J., 21: $518,2001$.

10- Saldanha O.R., De Souza Pinto E.B., Mattos W.N., et al.: Lipoabdominoplasty with selective and safe undermining. Aesthetic Plast. Surg., 27: 322-327, 2003.

11- Fang R.C., Lin S.J. and Mustoe T.A.: Abdominoplasty flap elevation in a more superficial plane: Decreasing the need for drains. Plast. Reconstr. Surg., 125 (2): 677-82, 2010.

12- Costa-Ferreira A., Rebelo M., Vásconez L.O. and Amarante J.: Scarpa fascia preservation during abdominoplasty: A prospective study. Plast. Reconstr. Surg., 125: 1232-1239, 2010.

13- Costa-Ferreira A., Rebelo M., Silva A., Vásconez L.O. and Amarante J.: Scarpa fascia preservation during abdominoplasty: Randomized clinical study of efficacy and safety. Plast. Reconstr. Surg., 131: 644-651, 2013. 
14- Koller M. and Hintringer T.: Scarpa fascia or rectus fascia in abdominoplasty flap elevation: A prospective clinical trial. Aesthetic Plast. Surg., 36 (2): 241-243, 2012

15- Di Martino M., Nahas F.X., Barbosa M.V., et al.: Seroma in lipoabdominoplasty and abdominoplasty: A comparative study using ultrasound. Plast. Reconstr. Surg., 126: 17421751,2010

16- Andrades P., Prado A., Danilla S., et al.: Progressive tension sutures in the prevention of post abdominoplasty seroma: A prospective randomized double-blind clinical trial. Plast. Reconstr. Surg., 120: 935-946; discussion 947-951, 2007.

17- Mladick R.A.: Progressive tension sutures to reduce complications in abdominoplasty. Plast. Reconstr. Surg., 107: 619-623, 2001.

18- Pollock H. and Pollock T.: Progressive tension sutures: A technique to reduce local complications in abdominoplasty. Plast. Reconstr. Surg., 105: 2583-2586; discussion 2587-2588, 2000.

19- Pollock T. and Pollock H.: Progressive tension sutures in abdominoplasty. Clin. Plast. Surg., 31: 583-589, 2004.

20- Khan U.D.: Risk of seroma with simultaneous liposuction and abdominoplasty and the role of progressive tension sutures. Aesthetic Plast. Surg., 32: 93-99; discussion 100, 2008.

21 - Kulber D.A., Bacilious N., Peters E.D., Gayle L.B. and Hoffman L.: The use of fibrin sealant in the prevention of seroma. Plast. Reconst. Surg., 99: 842, 1997.

22- Costa-Ferreira A., Rodrigues-Pereira P., Rebelo M.,
Vásconez L.O. and Amarante J.: Morphometric study (macroscopic and microscopic) of the lower abdominal wall. Plast. Reconstr. Surg., 134: 1313-1322, 2014.

23- Lancerotto L., Stecco C., Macchi V., Porzionato A., Stecco A. and De Caro R.: Layers of the abdominal wall: Anatomical investigation of subcutaneous tissue and superficial fascia. Surg. Radiol. Anat., 33: 835-842, 2011.

24- Tourani S.S., Taylor G. and Ashton M.W.: Scarpa Fascia Preservation in Abdominoplasty: Does It Preserve the Lymphatics? Plast. Reconstr. Surg., 136: 258-268, 2015.

25- Costa-Ferreira A., Rebelo M., Vásconez L. and Amarante J.: Scarpa fascia preservation during abdominoplasty. In: Di Giuseppe A., Shiffman M.A., eds. Aesthetic Plastic Surgery of the Abdomen. Cham, Switzerland: Springer, pp. 59-73, 2015.

26- Novais C.S., Carvalho J., Valença-Filipe R., et al.: Abdominoplasty with Scarpa Fascia Preservation: Randomized Controlled Trial with Assessment of Scar Quality and Cutaneous Sensibility. Plast. Reconstr. Surg., 146: $156 \mathrm{e}, 2020$.

27- Stoff A.: Comparing the ultrasonically activated scalpel (harmonic) with high-frequency electrocautery for postoperative serous drainage in massive weight loss surgery. Plast. Reconstr. Surg., 120: 1092, 2007.

28- Saldanha O.R., Federico R., Daher P.F., et al.: Lipoabdominoplasty. Plast. Reconstr. Surg., 124: 934, 2009.

29- Costa-Ferreira A., Rebelo M., Vásconez L.O., Amarante J.: Abdominoplasty with Scarpa Fascia Preservation. Ann. Plast. Surg., 76: S264-S274, 2016. 